\section{Pictorial fetal movement charts in a multiracial antenatal clinic}

\author{
M I Shafi, M S Dover, C A Dyer, P Byrne, \\ G Constantine, D M Luesley
}

Department of Obstetrics and Gynaecology, Dudley Road Hospital, Birmingham

M I Shafi, MRCOG, registrar P Byrne, MRCOG, registrar G Constantine, MRCOG, senior registrar

Medical School, University of Birmingham,

Birmingham

M S Dover, FDSRCS, medical student

C A Dyer, medical student

Department of Obstetrics and Gynaecology,

University of

Birmingham, Birmingham D M Luesley, MRCOG, senior lecturer

Correspondence to: $\mathrm{Dr}$ Shafi.

Br Med J 1989;298:1688
Fetal movement charts have been used extensively since their introduction in the 1970s. The "Cardiff count to ten" chart is the most popular, ${ }^{1}$ but in our multiracial population we have experienced problems with patients' understanding and of compliance in filling in this chart. In a previous analysis at Dudley Road Hospital $40 \%$ of patients could not explain how to fill it in correctly and $55 \%$ could not explain its importance (R I Cook and S L Eccleshall, unpublished data). Rates of compliance have been disappointing (mostly below 60\%). ${ }^{23}$ We devised a new chart, which

chart could explain the purpose of the charts at interview $\left(\chi^{2}=18 \cdot 2, p<0.0001\right)$. The findings were similar for all of the ethnic groups.

The women's perceptions of the charts were assessed with Likert linear scales. They found the pictorial chart significantly better explained and easier to complete and understand than the Cardiff chart $(p<0.001)$. The findings were similar in the 26 Asian patients, 11 of whom did not speak any English. A higher proportion of women completed the pictorial chart, and all of them did so correctly. All 12 Asian women completed the pictorial chart correctly compared with two (14\%) of those using the Cardiff chart.

\section{Comment}

In our multiracial population the Cardiff count to ten chart was poorly understood and a substantial number of patients were unable to fill in the chart correctly. The pictorial fetal movement chart helped

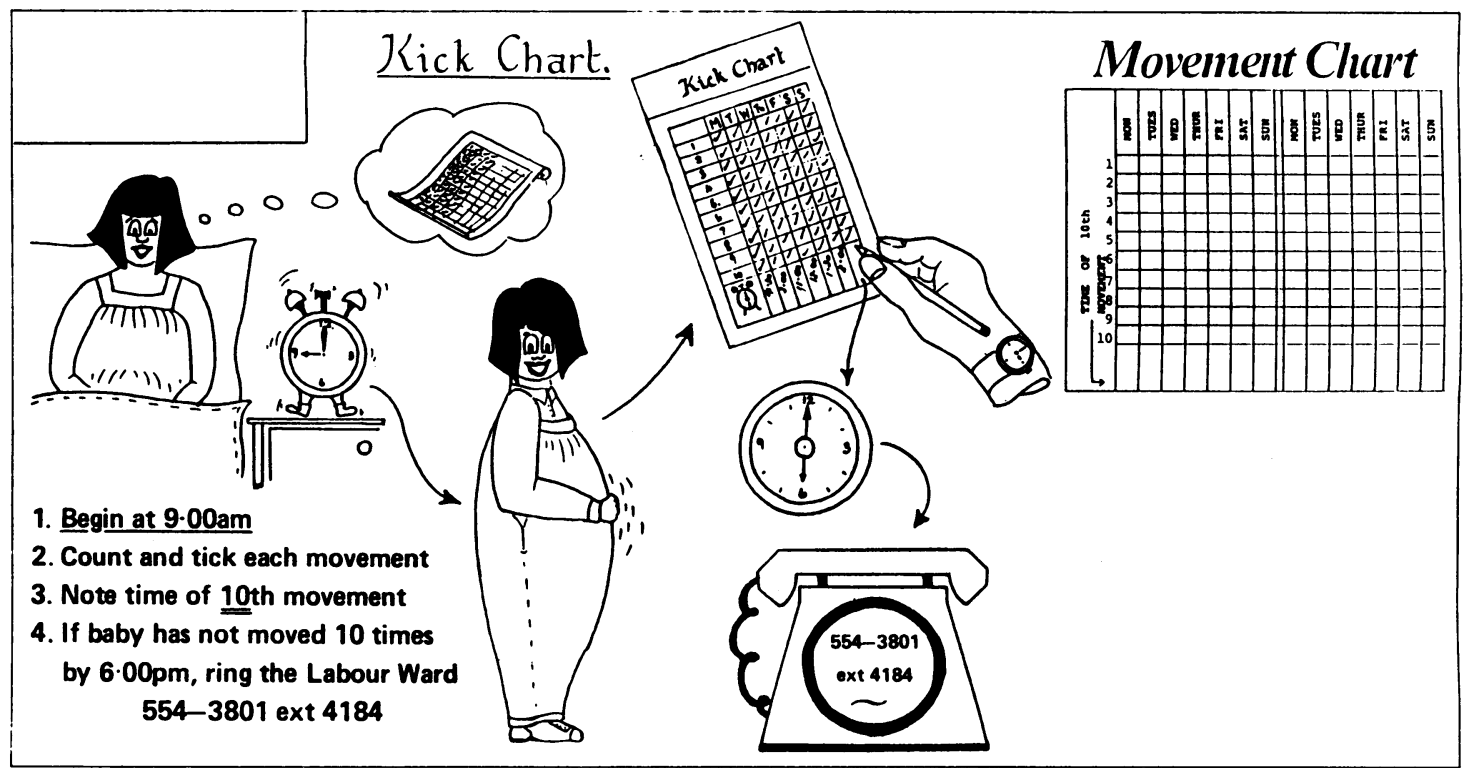

explains its use and importance in simple pictorial format, and performed a study to see if it was more understandable, especially to patients with a poor command of English

\section{Patients, methods, and results}

Patients in the third trimester were allocated randomly to receive either the Cardiff count to ten chart or the pictorial fetal movement chart (figure). Of the 125 patients entered into the study, 26 were of Asian origin, 28 were of Afro-Caribbean origin, and 71 of European origin. Explanations were given by the same staff in the same manner to each group. All patients were interviewed and interpreters used if necesssary.

Sixty eight women used the Cardiff count to ten chart and 57 the pictorial fetal movement chart during the study period. Both groups were similar in age, marital state, parity, gestation, and ethnic origin. Forty five women $(79 \%)$ who used the pictorial chart compared with $28(41 \%)$ women who used the Cardiff patients to assimilate the information and made its interpretation much easier. Fetal movement charts are a cheap and reliable method of screening fetal wellbeing. ${ }^{45} \mathrm{We}$ conclude that the pictorial chart is a distinct improvement on the Cardiff chart, and meets the needs of our local population more closely. Its introduction into other antenatal clinics is worth considering.

We thank Ms J A Pinkerton for her help in compiling the pictorial fetal movement chart.

1 Pearson JF, Weaver JB. Fetal activity and fetal wellbeing: an evaluation. Br Med f 1976;: 1305-7.

Anonymous. Do fetal movements reflect fetal wellbeing. [Editorial]. Br Med $\mathcal{J}$ 1981;282:588-9.

3 Thompson SL, Wheeler T. Compliance and maternal fetal movement counting. Lancet $1985 ; \mathrm{ii}: 1122$.

4 Sadovsky E, Yaffe H. Daily fetal movement recording and fetal prognosis. Obstet Gynecol 1973;41:845-50.

Manning FA, Platt LD, Sipos L. Fetal movements in human pregnancies in the third trimester. Obstet Gynecol 1979;54:699-702.

(Accepted 16 March 1989) 